\title{
MICROBIOLOGICAL ASSAY OF PANTOTHENIC ACID IN BLOOD AND URINE
}

\author{
MOTOHISA HATANO \\ The First Division, Department of Internal Medicine, \\ Faculty of Medicine, Kyoto University, Sakyo, Kyoto
}

(Received March 24, 1962)

The quantitative determination of pantothenic acid $(\mathrm{PaA})$ so far devised can be classified into two methods, i.e., chemical and microbiological. The former (1) is not sensitive enough for the measurement of $\mathrm{PaA}$ values of less than $1 \mathrm{mg} / \mathrm{ml}$. On the other hand, the latter is suitable for both urinary and blood $\mathrm{PaA}$, since it is possible to estimate the amounts of the vitamin as low as $10 \mathrm{~m} \mu \mathrm{g} / \mathrm{ml}$. The microorganisms available for the assay of the vitamin are Saccharomyces carlsbergenis (2), Proteus morganii (3), Streptococcus faecalis (4, 5), and Lactobacillus arabinosus. Among them, Lactobacillus arabinosus seems to give the least drift and good recovery for the assay $(6-8)$. For this reason, this organism was used in the present investigation. However, it should be kept in mind in the use of this organism for micrological assay that the organism fails to utilize the bound $\mathrm{PaA}$ such as pantethine, phosphopantethine and coenzyme A. Therefore, the bound forms have to be degraded into the free form preliminarily by enzymatic treatment for the determination of $\mathrm{PaA}$.

A number of researches (7) have hitherto been made on the PaA values in urine, whereas only a little has been done on the values in blood (8). Regarding the quantitative determination of the vitamin in blood so far presented by other investigators, there are roughly two investigations which contributed much to the assay, i.e., by Pennington (9) and by Fredrickson (10). The former deals with the blood $\mathrm{PaA}$, referring only to the free form, and the latter with the free and bound forms. Recently, it was found that the majority of the total $\mathrm{PaA}$ existed in the blood as the bound, active form.

It suggests that for the exploration of $\mathrm{PaA}$ metabolism, it is necessary to determine not only the free, but also the bound form. Thus the free and bound forms of the viatmin were quantitatively measured in the blood by the present author.

\section{EXPERIMENTAL}

The method used in this study is partially the same as described in the Pharmacopeia of the United States (12).

\section{Materials}

1. Standard Stock Solution of Calcium Pantothenate (12) 


\section{Medium}

Stock Culture Medium-The medium (Table I) pertinent to the PaA assay was employed in this study. A $6 \%$ solution of the medium was made and autoclaved at 15 pounds $\left(120^{\circ}\right)$. A fresh stab of the stock culture was prepared every week and was used for inoculation.

TABLE I

Stock Culture Medium

\begin{tabular}{lrlr}
\hline Component & Content & \multicolumn{1}{c}{ Component } & Content \\
\hline Yeast extract & $5 \mathrm{~g}$ & Sodium acetate & $10 \mathrm{~g}$ \\
Peptone & $10 \mathrm{~g}$ & $\mathrm{MgSO}_{4} \cdot 7 \mathrm{H}_{2} \mathrm{O}$ & $0.1 \mathrm{~g}$ \\
$\mathrm{Glucose}_{\mathrm{K} \mathrm{H}_{2} \mathrm{PO}_{4}}^{10 \mathrm{~g}}$ & $0.25 \mathrm{~g}$ & $\mathrm{MnSO}_{4} \cdot 7 \mathrm{H}_{2} \mathrm{O}$ & $5 \mathrm{mg}$ \\
$\mathrm{K}_{2} \mathrm{HPO}_{4}$ & $0.25 \mathrm{~g}$ & Agar & $5 \mathrm{mg}$ \\
\end{tabular}

Basal Medium ${ }^{1}$ _...As shown in Table II, $7.7 \mathrm{~g}$ of powdered basal medium was dissolved in $100 \mathrm{ml}$ of distilled water. $2.5 \mathrm{ml}$-aliquots of the solution and $2.5 \mathrm{ml}$ of the standard solution of the sample were pipetted into the test tubes and was autoclaved at 15 pounds.

TABLE II

Basal Medium

\begin{tabular}{lclc}
\hline \multicolumn{1}{c}{ Component } & Content & \multicolumn{1}{c}{ Component } & Content \\
\hline Acid-hydrolyzed casein & $10 \mathrm{~g}$ & p-Aminobenzoic acid & $200 \mu \mathrm{g}$ \\
L-Cysteine & $400 \mathrm{mg}$ & Nicotinic acid & $400 \mu \mathrm{g}$ \\
DL-Tryptophane & $200 \mathrm{mg}$ & Ryridoxine hydrochloride & $800 \mu \mathrm{g}$ \\
Adenine sulfate & $20 \mathrm{mg}$ & $\mathrm{KH}_{2} \mathrm{PO}_{4}$ & $1 \mathrm{~g}$ \\
Guanine hydrochloride & $20 \mathrm{mg}$ & $\mathrm{K}_{2} \mathrm{HPO}_{4}$ & $1 \mathrm{~g}$ \\
Uracil & $20 \mathrm{mg}$ & $\mathrm{MgSO}_{4} \cdot 7 \mathrm{H}_{2} \mathrm{O}$ & $400 \mathrm{mg}$ \\
Thiamine hydrochloride & $200 \mu \mathrm{g}$ & $\mathrm{MgSO}_{4} \cdot 4 \mathrm{H}_{2} \mathrm{O}$ & $20 \mathrm{mg}$ \\
Riboflavin & $400 \mu \mathrm{g}$ & Sodium acetate & $20 \mathrm{~g}$ \\
Biotin & $0.8 \mu \mathrm{g}$ & Glucose & $40 \mathrm{~g}$ \\
\hline
\end{tabular}

Inoculation Medium-Inoculation medium used in this study is the stock medium, from which agar has been excluded.

Sterilization of a $4 \%$ solution of the inoculation medium was likewise made similarly to the basal and stock culture media.

\section{Inoculum}

On the day before inoculation, the organism was transferred to the inoculation medium from a stock culture medium of Lactobacillus arabinosus, and was incubated for 24 hours at $37^{\circ}$.

Thereafter, the organism grown on the inoculation medium was washed repeatedly with sterilized physiological saline solution by centrifugation, and then adjusted the suspension to the transmittance of 60-90\%.

The organism suspension thus obtained is the inoculum.

Made with the preparation of Nissan Suisan Company or that of Difco Laboratories. 


\section{Methods}

One drop of the inoculum was added to the test tube containing the sterilized solutions of $2.5 \mathrm{ml}$ basal medium and $2.5 \mathrm{ml}$ standard solution $(40 \mathrm{~m} \mu \mathrm{g}$ of $\mathrm{PaA}$ per $\mathrm{ml}$ ) or sample. Incubation was made for 72 hours at a temperature of $37^{\circ}$.

For the purpose of measuring the lactic acid, produced during the bacterial growth in the tube, acidometry was carried out with $0.1 \mathrm{~N} \mathrm{NaOH}$ using phenolphthalein as an indicator. Fig. 1 is a standard curve obtained by using the standard media.

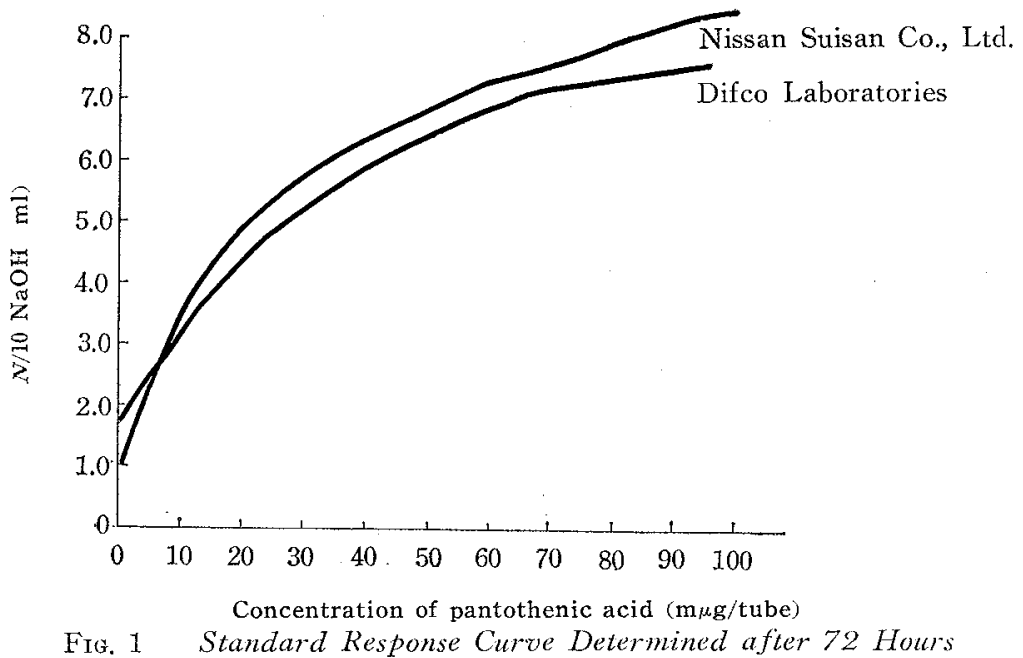

\section{Determination of Blood Pantothenic Acid}

Treatment of Blood for the Measurement of the Free Form-Blood was withdrawn from the antecubital vein, and oxalate mixture was immediately added to the blood in proportions of $5-10 \mathrm{mg}$ per $5 \mathrm{ml}$ of blood, and the mixture was kept in the frozen state. For the measurement of the free form of the vitamin, it was diluted with an adequate amount of water at room temperature.

Each of $0.5,1.0$ and 2.0 aliquots of the solution was pipetted into the test tubes and water was added to a final volume of $5.0 \mathrm{ml}$.

Treatment of Blood for the Measurement of Total PaA_-One ml of oxalated blood was added to $0.4 \mathrm{ml}$ of the solution diluted to half the concentration of Lipmann's original enzymatic solution (13-16). This mixture was incubated for 24 hours at $37^{\circ}$, and was diluted with water adequately.

Preparation of Lipmann's original enzymatic solution (13-16): Extract of pigeon liver, $2 \%$ intestinal phosphatase solution and $1 M$ Tris hydroxymethyl aminomethane ( $\mathrm{pH} 8.3$ ) mixed in a proportion of $2: 1: 1$. values.

Bound $\mathrm{PaA}$ was calculated as the difference between the total and the free 


\section{Technical Consideration for Blood PaA Determination}

Relation of the Added Amount of Oxalate Mixture to the Recovery-The effects of oxalate mixtures at various concentrations on the recovery of the known amounts of $\mathrm{PaA}$ was scarcely recognizable so long as the amounts of oxalates added to the medium were below $7 \mathrm{mg}$ (Table III).

\section{TABLE III}

Effect of Oxalate Mixture on Pantothenic Acid Values

Oxalate mixture consisting of $62.5 \%$ ammonium oxalate and $37.5 \%$ potassium oxalate was used.

\begin{tabular}{cc}
\hline Oxalate mixture & $\begin{array}{c}\text { Pantothenic } \\
\text { acid value }\end{array}$ \\
\hline$m \mu g / m l$ & $m \mu g / m l$ \\
0 & 40 \\
1 & 40 \\
2 & 40 \\
3 & 40 \\
4 & 40 \\
5 & 40 \\
6 & 42 \\
7 & 43
\end{tabular}

This result supports the validity of the author's method, i.e., the effect of the added oxalate mixture was quite negligible, since the blood sample was so diluted that it contained less than $2 \mathrm{mg}$ of the mixture.

Influence of the Freezing of Blood on PaA Recovery- The PaA estimations were carried out on the samples as cold as possible in order to avoid its autolysis. The samples were kept below $0^{\circ}$ in the refrigerator to freeze for various times in order to test any effect of freezing time on the recovery of the PaA value. The determinations were performed at each time interval of freezing. It was found that no fluctuations of the values occurred if the freezing time was within 30 days. In this study the blood $\mathrm{PaA}$ values were determined within 30 days after vienesection.

Influence of Autolysis-B.-Blood samples were kept at room temperature or at $37^{\circ}$ for various hours (Table IV). After 72 hours, the $\mathrm{PaA}$ value recovered from the sample increased up to $273 \mathrm{~m} \mu \mathrm{g} / \mathrm{ml}$, indicating a marked increase of the free form as compared with the value determined immediately after venesection. This increase may probably result from autolysis. Therefore, the free form was measured as soon as possible to avoid the effect of autolysis.

TABLE IV

Effect of Autolysis on the Pantothenic Acid Levels in Blood

\begin{tabular}{|c|c|c|c|c|c|c|c|c|}
\hline \multicolumn{2}{|c|}{ Condition } & \multicolumn{7}{|c|}{ Pantothenic acid levels in blood after hours } \\
\hline Temperature & $\mathrm{pH}$ & 0 & 3 & 12 & 24 & 48 & 72 & 96 \\
\hline${ }^{\circ} \mathrm{C}$ & \multicolumn{8}{|c|}{$m \mu g$ per $m 1$} \\
\hline 16,27 & 7.0 & 25 & 29 & 42 & 101 & 143 & 161 & 164 \\
\hline 37 & 7.0 & 25 & 48 & 71 & 199 & 254 & 273 & 257 \\
\hline
\end{tabular}


TABLE V

Time Necessary to Exert Enzymatic Activity

\begin{tabular}{cccccc}
\hline \multirow{2}{*}{$\begin{array}{c}\text { Sample } \\
\text { No. }\end{array}$} & \multicolumn{5}{c}{ Pantothenic acid levels in blood after hours } \\
\cline { 2 - 6 } & 0 & 4 & 8 & 16 & 24 \\
\hline & & & m $\mu g$ per $m l$ & 435 \\
2 & 23 & 398 & 429 & 434 & 441 \\
3 & 25 & 411 & 437 & 435 & 483 \\
Mean & 27 & 418 & 484 & 490 & $\mathbf{4 5 3}$ \\
\hline
\end{tabular}

Duration of Time Necessary to Exert Enzymatic Activity-Blood sample were treated according to Lipmann for various periods. As shown in Table V, it was suggested that the enzymatic treatment should be made at least for 16 hours. Thus the enzymatic treatment for 24 hours was adopted by the author throughout the study.

Effect of Concentration of Enzyme - As shown in Table VI, it was found that the treatment with the enzymes of half the concentration of Lipmann's original solution gave the least fluctuation for $\mathrm{PaA}$ values and besides the enzymatic activity. The method was proved to be satisfactory for the determination. Accordingly, half the concentration of Lipmann's original solution was used for the measurement.

TABLE VI

Effect of Concentration of Enzyme

\begin{tabular}{cccc}
\hline & \multicolumn{3}{c}{ Lipmann's enzymatic solution } \\
\cline { 2 - 4 } Sample No. & $\begin{array}{c}\text { Standard } \\
\text { concentration }\end{array}$ & Half \\
& \multicolumn{4}{c}{ concentration } \\
Pantothenic acid levels in blood (mug per ml) \\
1 & 405 & 430 & $1 / 4$ \\
2 & 450 & 440 & 425 \\
3 & 435 & 450 & 420 \\
4 & 440 & 425 & 445 \\
Mean & $\mathbf{4 3 2 . 5}$ & $\mathbf{4 3 2 . 5}$ & 410 \\
& & & 425.6 \\
\hline
\end{tabular}

\section{Determination of Free and Bound Forms of PaA in Urine}

Treatment of Urine- Twenty four hour-urine was kept by adding toluene until used. The collected urine was not subjected to freezing or mixed with oxalate mixture. The determination of the free form in the urine was made without enzymatic treatment.

\section{4. 'Technical Consideration of Urinary PaA Determination}

Influence of Light and Temperature on Urinary PaA-The collected urine was divided into two parts. One was kept $30 \mathrm{~cm}$ below a 5 -watt electric bulb at $37^{\circ}$, while the other was kept in a dark room at $0^{\circ}$ for 24 hours. The PaA values obtained from the two urine samples were approximately identical, 5.4 $\mathrm{m} \mu \mathrm{g} / \mathrm{ml}$. This fact shows that the urinary values are influenced neither by light nor by temperature. So the urinary $\mathrm{PaA}$ determination was made at room temperature in the ordinary laboratory. 


\section{RESULTS}

\section{PaA Levels in the Total Blood of Healthy Subjects}

A survey was made on 30 healthy persons of both sexes whose ages ranged from 15 to 50. Table VII shows the PaA values of the whole blood in the fasting state. The total value was found to be 364.5 to 540.0 , with an average of 464.2 $\mathrm{m} \mu \mathrm{g} / \mathrm{ml}$. The bound form was 351.0 to 490.0 , with a mean of $435.5 \mathrm{~m} \mu \mathrm{g} / \mathrm{ml}$, while the free form was 28.7 on the average, ranging from 14.0 to $70.0 \mathrm{~m} \mu \mathrm{g} / \mathrm{ml}$.

TABLE VII

Pantothenic Acid Levels in Normal Persons

\begin{tabular}{|c|c|c|c|c|c|c|c|c|c|}
\hline \multirow{3}{*}{ No. } & \multirow{3}{*}{ Age } & \multirow{3}{*}{ Sex } & \multicolumn{7}{|c|}{ Pantothenic acid levels } \\
\hline & & & Free & Bound & Total & $\mathrm{B} / \mathrm{T}$ & Free & Bound & Total \\
\hline & & & & \multicolumn{3}{|c|}{ Blood } & \multicolumn{3}{|c|}{ Urine } \\
\hline & & & & \multicolumn{3}{|c|}{$m_{l^{\prime}} g$ per $m l$} & \multicolumn{3}{|c|}{ mıtg per day } \\
\hline 1 & 20 & $\mathrm{~m}$ & 40 & 420 & 460 & 0.91 & 3.53 & 0.00 & 3.53 \\
\hline 2 & 30 & $\mathrm{~m}$ & 40 & 410 & 450 & 0.91 & 3.44 & 0.01 & 3.45 \\
\hline 3 & 31 & $\mathrm{~m}$ & 60 & 450 & 510 & 0.88 & 3.06 & 0.03 & 3.09 \\
\hline 4 & 32 & $\mathrm{~m}$ & 40 & 410 & 450 & 0.91 & 2.67 & -0.01 & 2.66 \\
\hline 5 & 29 & $\mathrm{~m}$ & 15 & 450 & 465 & 0.97 & 3.73 & 0.08 & 3.81 \\
\hline 6 & 28 & $\mathrm{~m}$ & 30 & 405 & 435 & 0.93 & 2.47 & -0.10 & 2.37 \\
\hline 7 & 27 & $m$ & 30 & 480 & 510 & 0.94 & 2.52 & -0.01 & 2.51 \\
\hline 8 & 26 & $\mathrm{~m}$ & 15 & 440 & 455 & 0.97 & 4.28 & 0.00 & 4.28 \\
\hline 9 & 28 & $\mathrm{~m}$ & 45 & 370 & 415 & 0.89 & 3.98 & 0.00 & 3.98 \\
\hline 10 & 15 & $\mathrm{~m}$ & 30 & 450 & 480 & 0.94 & 3.42 & 0.00 & 3.42 \\
\hline 11 & 35 & $\mathrm{~m}$ & 15 & 470 & 485 & 0.97 & 4.46 & 0.00 & 4.46 \\
\hline 12 & 50 & $\mathrm{~m}$ & 20 & 400 & 420 & 0.95 & 3.45 & -0.01 & 3.44 \\
\hline 13 & 42 & $\mathrm{~m}$ & 25 & 490 & 515 & 0.95 & 2.54 & 0.02 & 2.56 \\
\hline 14 & 41 & $\mathrm{~m}$ & 70 & 440 & 510 & 0.86 & 3.35 & 0.02 & 3.37 \\
\hline 15 & 17 & $\mathrm{~m}$ & 60 & 480 & 540 & 0.89 & 3.25 & 0.03 & 3.26 \\
\hline 16 & 25 & $f$ & 15 & 480 & 495 & 0.97 & 2.57 & 0.01 & 2.58 \\
\hline 17 & 23 & $\mathrm{f}$ & 20 & 480 & 500 & 0.96 & 2.46 & 0.01 & 2.47 \\
\hline 18 & 24 & $\mathrm{f}$ & 15 & 470 & 485 & 0.97 & 2.54 & 0.02 & 2.56 \\
\hline 19 & 25 & $f$ & 25 & 440 & 465 & 0.94 & 2.52 & 0.03 & 2.55 \\
\hline 20 & 27 & $\mathrm{f}$ & 40 & 480 & 520 & 0.92 & 2.58 & -0.01 & 2.59 \\
\hline 21 & 21 & $\mathrm{f}$ & 17 & 4.58 & 475 & 0.96 & 2.83 & 0.01 & 2.84 \\
\hline 22 & 18 & $\mathrm{f}$ & 21.5 & 410 & 431.5 & 0.95 & 3.27 & 0.01 & 3.28 \\
\hline 23 & 45 & $\mathrm{f}$ & 24.5 & 440 & 464.5 & 0.95 & 4.05 & -0.02 & 4.03 \\
\hline 24 & 50 & $\mathrm{f}$ & 13.5 & 351 & 364.5 & 0.96 & 3.65 & 0.00 & 3.65 \\
\hline 25 & 18 & $f$ & 17.5 & 388 & 405.5 & 0.96 & 3.03 & 0.00 & 3.03 \\
\hline 26 & 19 & $\mathrm{f}$ & 27.5 & 381 & 408.5 & 0.93 & 3.07 & 0.04 & 3.07 \\
\hline 27 & 18 & $\mathrm{f}$ & 14 & 381 & 395 & 0.99 & 3.71 & -0.01 & 3.70 \\
\hline 28 & 15 & $f$ & 16.5 & 472 & 488.5 & 0.97 & 2.99 & 0.02 & 3.02 \\
\hline 29 & 32 & f & 24. & 425 & 449 & 0.95 & 4.06 & 0.05 & 4.11 \\
\hline 30 & 35 & $\mathrm{f}$ & 35 & 445 & 480 & 0.93 & 3.34 & 0.02 & 3.36 \\
\hline & & & 14.0 & 351.0 & 364.5 & 0.86 & 2.46 & -0.10 & 2.37 \\
\hline Range & & & $\begin{array}{l}\text { to } \\
70.0\end{array}$ & $\begin{array}{c}\text { to } \\
490.0\end{array}$ & $\begin{array}{c}\text { to } \\
540.0\end{array}$ & $\begin{array}{l}\text { to } \\
0.97\end{array}$ & $\begin{array}{l}\text { to } \\
4.46\end{array}$ & $\begin{array}{c}\text { to } \\
0.08\end{array}$ & $\begin{array}{l}\text { to } \\
4.46\end{array}$ \\
\hline Tean & & & 28.7 & 435.5 & 464.2 & 0.94 & 3.23 & 0.08 & 3.23 \\
\hline - S.D. & & & \pm 15 & $\begin{array}{l} \pm 7 \\
\pm 37\end{array}$ & \pm 41 & \pm 0.2 & \pm 0.6 & $+\mathbf{0 . 0 3}$ & +0.6 \\
\hline
\end{tabular}

\section{Urinary PaA Levels in Healthy Subjects}

In 30 healthy persons, the $\mathrm{PaA}$ levels in 24-hour urines are shown in Table VII. The total value was 2.37 to 4.46 , with an average of $3.23 \mathrm{mg}$. The majority of urinary $\mathrm{PaA}$ was in the free form. 


\section{DISCUSSION}

Quantitative measurement of $\mathrm{PaA}$ was carried out by a microbiological assay using Lactobacillus arabinosus on human blood and urine specimens. In this study, Lipmann's original enzymatic solution was diluted to half the concentration. As a result, thus diluted enzymatic solution brought forth a lower blank value, giving the least variability in $\mathrm{PaA}$ values. The dilution seems to have reduced the amount of $\mathrm{PaA}$ present in Lipmann's original solution, preserving the enzymatic activity. As for the collection of urine, almost no influence was observed on the enzymatic activity of the solution even when the urine was kept at a distance of $30 \mathrm{~cm}$ below a 5 -watt globe at $37^{\circ}$. Thus it was suggested that the measurement could be successfully carried out, as long as the urine specimens were collected at room temperature.

Regarding the determination of bound $\mathrm{PaA}$ in the blood, Fredrickson (10) also used Lipmann's solution and found that the bound form in healthy persons was $461 \pm 27 \mathrm{~m} \mu \mathrm{g} / \mathrm{ml}$ on the average, a value approximately in agreement with that of the present author.

However, when a blood sample was subjected to autolysis instead of enzymatic treatment, the value obtained was much less, $273 \mathrm{~m} \mu \mathrm{g} / \mathrm{ml}$. These discrepancies were found also after different treatments of blood $\mathrm{PaA}$. At any event, the enzymatic treatment of a blood sample seems to give more precise values. Therefore, the author feels it better to perform the enzymatic treatment rather than autolysis to measure more exactly the bound form of the vitamin in the blood.

As regards the free form of the vitamin in the blood, Fredrickson reported the value of $116 \pm 23 \mathrm{~m} \mu \mathrm{g} / \mathrm{ml}$ in healthy adults, while the present author found $28.7 \mathrm{~m} \mu \mathrm{g} / \mathrm{ml}$. But, the presents author's value obtained from the blood sample left for 48 hours at room temperature was 101 to $143 \mathrm{~m} \mu \mathrm{g} / \mathrm{ml}$, which is rather close to Fredrickson's and the increase is possibly due to autolysis. The possible explanation for this difference or accord is that, $(a)$ presumably Fredrickson himself also has left the blood sample for more than 48 hours or so prior to the measurement, whereby the above described similarity was obtained, $(b)$ the technique used by Fredrickson may be different from the author's, which may give rise to the difference, and $(c)$ the difference may actually be due to the species difference.

As a matter of fact, to freeze the blood as soon as possible after the withdrawal could prevent the bound form from autolysis.

As regards the total $\mathrm{PaA}$ in blood, Baker (17) found the value of 470-560 $\mathrm{m} \mu \mathrm{g} / \mathrm{ml}$, whereby Clarase was used instead of Lipmann's enzymes. But this value is approximately in good keeping with the total values of $465 \mathrm{~m} \mu \mathrm{g} / \mathrm{ml}$ by the author.

It has been reported by many investigators that the $\mathrm{PaA}$ found in the urine of healthy persons is entirely the free form. The present author's results suggest that the $\mathrm{PaA}$ value of the free form and the total in the urine of healthy persons is the same, since there is no bound form. There has been no report on the total $\mathrm{PaA}$ value obtained after enzymatic treatment of urine, though a large number of reports have been made on the free form obtained without enzymatic treatment, 
as Baker (17), Schmidt (18), Wright (19), Krahnke (20), Sarett (21), Gershbery (22), Gounell (23), Pelezar (24), Burlet (25), Fitzpatrick (26), Kawai (27), and Ueshima (28). The values reported by these investigators range from 2.6 to $5.7 \mathrm{mg} /$ day. The author's value of the free form was also within this range.

\section{SUMMARY}

Quantitative determination of pantothenic acid in blood and urine was made, fractionating into the free and bound forms and the following results were obtained.

1. It was found that total pantothenic acid was measurable with the use of Lipmann's enzymes, while the free form can be determined without enzymatic treatment. The bound form, therefore, could be calculated by subtracting the free form from the total value.

2. It was found that better results were obtained with half the concentration of Lipmann's solution.

3. Enzymatic treatment gave higher total values than autolysis, indicating the importance of enzymatic treatment.

4. Since the bound pantothenic acid in the blood could be degraded, in part, into the free form by autolysis, it is necessary that the measurement of the free form should be made as soon as possible to avoid autolysis.

5. The total pantothenic acid levels in the blood of 30 healthy adults were found to be $464.2 \pm 41$, the bound form $435.5 \pm 37$, and the free form $28.7 \pm 15 \mathrm{~m} \mu \mathrm{g} / \mathrm{ml}$.

6. The total urinary pantothenic acid of adults was $3.24 \pm 0.6$, and the free form $3.23 \pm 0.6 \mathrm{mg} /$ day, suggesting that the enzymatic treatment is not necessary, since urinary pantothenic acid is predominantly in the free form.

\section{A CKNOWLEDGEMENT}

The author wishes to express his sincere appreciation to the Emeritus Professor Katashi Inouye and Professor Gyoichi Wakisaka for their constant interests and guidance in this investigation and to Drs. Eisuke Katura, Akima Miyoshi and Haruto Uchino for their constant advice. To the staff of Daiichi Seiyaku Co., Ltd., the author is particularly grateful, for, without their supply of valuable materials, this study would have been impossible.

\section{REFERENCES}

1. Wollish, E. G., and Schmall, M., Anal, Chem. 22, 1033 (1950).

2. Atkin, L., Williams. W. L., Schultz, A. S, and Frey. C. N., Ind. Eng. Chem. Anal. Ed. 16, 67 (1944).

3. Pelczar, M.J., and Porter, J.R., J. Biol. Chem. 139, 111 (1941), Proc. Soc. Exptl. Biol. Med. 47, 3 (1941).

4. Kocher, V., Z. Vitaminforschung 16, 113 (1945).

5. Robinowitz, J. C., J. Biol. Chem. 169, 631 (1947).

6. Snell, E. E., and Wright, L. D., ibid 139, 675 (1941).

7. Skeggs, H. R, and Wright, L. D., ibid 156, 21 (1944)

8. Hoag, E. H., Sarett, H. P., and Cheldelim, V.H., Ind. Eng. Chem. Anal. Ed. 17, 60 (1945). 
9. Pennington, D., Snell, E. E., and Williams, R. J., J. Biol. Chem. 135, 213 (1940).

10. Slepyan, A. H., Forst, D. V., Overly, L. R., Fredickson, R. L., and Osterberg, A. E., Arch. Dermatol. 75, 845 (1957).

11. Kaplan, N. O., and Lipmann, F., J. Biol. Chem. 174, 37 (1948).

12. Pharmacopeia of the United States 15, 861 (1955).

13. Neal, A. L., and Strong, F. M., Ing. Eng. Chem. Anal. Ed. 15, 654 (1943).

14. Light, A. E., and Clarhe, M. F., J. Biol. Chem. 147, 739 (1943).

15. Ives, M., J. Am. Diet. Assoc. 21, 357 (1945).

16. Roberts, E. C., and Snell, E. E., J. Biol. Chem. 163, 499 (1916).

17. Baker, H., Frank, O., Pasher, I., Dinnerstein, A., and Sobotka, H., American Association of Clinical Chemists 6, 37 (1960).

18. Schmidt, V., Acta Med. Scand. 134, 185 (1951); Scand. J. Clin. Lab. Invest. 3, 108 (1951).

19. Wright, L.D.. and Wright, E. Q., Proc. Soc. Exptl. Biol. Med. 145, 633 (1946); Skeggs. H. R., and Wright, L. D., J. Biol. Chem. 156, 21 (1944).

20. Krahnke, H., and Gordon, E. S., J. Am. Med. Ass. 116, 2431 (1941).

21. Sarett, H.P., J. Biol. Chem. 129, 321 (1945).

22. Gershberg, H., Rubin, S. H., and Ralli, E. P., J. Nutrition 39, 107 (1949).

23. Gounell, H. and Richet, F., Compt. rend. soc. biol. 151, 24 (1957).

24. Pelezar, M. J., and Porter, J. R, Proc. Soc. Exptl. Biol. Med. 49, 80 (1942).

25. Burlet. E., Ztschr. Vitaminforsch. 14, 318 (1944).

26. Fitzpatrick, J., and Tompsett, S. L., J. Clin. Path. 3, 69 (1950).

27. Kawai. H., J. Chiba Med. Soc. 33, 596 (1957).

28. Ueshima, T., Vitamins 10, 108 (1956). 